OPEN ACCESS

Edited by:

Kevin J. Ni,

St George Hospital, Australia

Reviewed by:

Xi Yang,

Fudan University, China

Guo-Kai Feng,

Sun Yat-sen University Cancer Center

China

*Correspondence:

Guanghui Cheng

chenggh@jlu.edu.cn

Specialty section:

This article was submitted to

Molecular and Cellular Oncology,

a section of the journal

Frontiers in Cell and Developmental

Biology

Received: 28 December 2020

Accepted: 24 March 2021

Published: 13 April 2021

Citation:

Yu X, Liu B, Zhang N, Wang $Q$ and Cheng $G$ (2021) Immune Response: A Missed Opportunity Between Vitamin D and Radiotherapy.

Front. Cell Dev. Biol. 9:646981. doi: $10.3389 /$ fcell.2021.646981

\section{Immune Response: A Missed Opportunity Between Vitamin D and Radiotherapy}

\author{
Xinyue Yu, Baocai Liu, Ning Zhang, Qian Wang and Guanghui Cheng* \\ Department of Radiation Oncology, China-Japan Union Hospital of Jilin University, Changchun, China
}

Radiotherapy (RT) is a mainstay treatment in several types of cancer and acts by mediating various forms of cancer cell death, although it is still a large challenge to enhance therapy efficacy. Radiation resistance represents the main cause of cancer progression, therefore, overcoming treatment resistance is now the greatest challenge for clinicians. Increasing evidence indicates that immune response plays a role in reprogramming the radiation-induced tumor microenvironment (TME). Intriguingly, radiation-induced immunosuppression possibly overwhelms the ability of immune system to ablate tumor cells. This induces an immune equilibrium, which, we hypothesize, is an opportunity for radiosensitizers to make actions. Vitamin D has been reported to act in synergistic with RT by potentiating antiproliferative effect induced by therapeutics. Additionally, vitamin D can also regulate the TME and may even lead to immunostimulation by blocking immunosuppression following radiation. Previous reviews have focused on vitamin D metabolism and epidemiological trials, however, the synergistic effect of vitamin $D$ and existing therapies remains unknown. This review summarizes vitamin $D$ mediated radiosensitization, radiation immunity, and vitamin D-regulated TME, which may contribute to more successful vitamin D-adjuvant radiotherapy.

Keywords: vitamin $\mathrm{D}$, calcitriol, radiation, radiotherapy, immune response, tumor microenvironment

\section{INTRODUCTION}

Radiotherapy (RT) is usually the definitive treatment for many types of tumors, including but not limited to colorectal cancer, nasopharyngeal carcinoma, and cervical cancer (Chen et al., 2019; Cohen et al., 2019; Dekker et al., 2019). Resistance to radiation is considered to be an important reason for tumor recurrence and local failure, different cell molecular mechanisms are involved in intrinsic and acquired resistance of cancer cells to therapeutics. Although some strategies, such as radiosensitizers, have been investigated recently, sensitizers have been limited to preclinical studies due to the toxic effects of these agents.

Vitamin D, which is a fat-soluble secosteroid mediating numerous physiological functions (Maurya et al., 2020), has been demonstrated to participate in antitumor activity in many cancers (Keum et al., 2019). Moreover, accumulating data suggest that vitamin D employs several mechanisms to enhance the elimination of irradiated tumor cells (Sundaram and Gewirtz, 1999; Chaudhry et al., 2001; Bristol et al., 2012; Sharma et al., 2014). Thus, a deeper understanding of how 
vitamin D functions in combination with $\mathrm{RT}$ in cancer may help in developing effective sensitizers to overcome radioresistance.

It is worth noting that the immune system plays an important role in the response to RT (Chen et al., 2019). Radiation can lead to both positive and negative regulation of the immune response, and this has been observed not only in tumor cells but also in the tumor microenvironment (TME). Importantly, vitamin D is also involved in the immune microenvironment (Charoenngam and Holick, 2020), although the underlying mechanism has not been clearly elucidated.

Although there is growing awareness of the importance of vitamin $\mathrm{D}$ in tumor cell response to radiation, there have been few reviews to report the underlying mechanisms. In this review, we briefly introduce vitamin $\mathrm{D}$ and the mechanisms influencing radiosensitivity. Additionally, we discuss how the immune response is regulated in response to RT. Finally, we present the modulation of TME by vitamin $\mathrm{D}$ and speculate on the intricate association among vitamin $\mathrm{D}$, radiation, and anti-tumor immunity.

\section{VITAMIN D METABOLISM AND EPIDEMIOLOGY}

Vitamin D is produced from 7-dehydrocholesterol in the human skin after exposure to ultraviolet radiation in sunlight, therefore, it can be influenced by season, latitude, skin pigmentation, and cultural habits. In addition, dietary habits and supplementation can also affect vitamin D levels (Amrein et al., 2020). A twostep catalysis mediated by cytochrome P450 is the crucial process in the production of the steroid hormone calcitriol (biologically active form of vitamin D) (Jones et al., 2014). The less active form of vitamin $\mathrm{D}, 25(\mathrm{OH}) \mathrm{D}_{3}$, is generated after the first hydroxylation by vitamin D 25-hydroxylase (CYP2R1 and CYP27A1) in the liver (Bikle, 2014). 25(OH) $\mathrm{D}_{3}$ is found to be the major circulating form of vitamin $\mathrm{D}$ in the blood, however, general agreement on the threshold levels has not been defined. Recently, 25(OH)D levels of 75-150 nmol/L (30-60 ng/mL) have been proposed to be the optimal range for vitamin $\mathrm{D}$ (BischoffFerrari et al., 2016). The association between 25(OH)D level and cancer risk has been described in several solid cancers (Yao et al., 2017; Ramakrishnan et al., 2019; Yuan et al., 2019), and higher $25(\mathrm{OH}) \mathrm{D}$ circulating level contributes to better prognosis in colorectal cancer (Markotic et al., 2019). Subsequently, the kidneys utilize the circulating $25(\mathrm{OH}) \mathrm{D}_{3}$ as a substrate and convert it into 1,25-dihydroxy-vitamin D3, which is hydroxylated by CYP27B1 (Jones et al., 2014).

Previous finding supports the role of CYP24A1 in catabolizing $25(\mathrm{OH}) \mathrm{D}$ and preventing the formation of $1,25(\mathrm{OH})_{2} \mathrm{D}_{3}$ (Jones et al., 2012). Interestingly, either activation of the catabolic enzyme CYP24A1 by calcidol or calcitriol or inactivation of CYP27B1 by calcitriol can lead to a negative feedback loop to regulate the vitamin $\mathrm{D}$ level, broadening the role of CYP24A1 as an important mediator of the rate limiting step of not only vitamin $\mathrm{D}$ generation but also hormone selfregulation, thus potentially ameliorating hypercalcemia. The hypercalcemia induced by an increased concentration of calcitriol or insufficiency in the blood due to its instability can undoubtedly limit its clinical application. This has eventually led to the exploration of calcitriol analogs that can exert equipotent or increased anticancer actions with less side effects (Jones, 2010).

$1,25(\mathrm{OH})_{2} \mathrm{D}_{3}$ is able to regulate the expression of several genes depending on the tissues, cell types, and context (Carlberg and Munoz, 2020). By binding to vitamin D receptor (VDR), $1,25(\mathrm{OH})_{2} \mathrm{D}_{3}$ facilitates dimerization with the retinoid $\mathrm{X}$ receptor (RXR), which fosters nuclear translocation of this complex, and subsequent binding to the vitamin $\mathrm{D}$ response elements (VDREs) in the target gene, followed by recruitment of comodulators. Therefore, calcitriol can interfere with target gene expression in the genomic pathway (Carlberg and Munoz, 2020). It functions in the genomic way by which $1,25(\mathrm{OH})_{2} \mathrm{D}_{3}$-VDRRXR complex is involved, and the non-genomic way, by which a 1,25D-membrane-associated, rapid response steroid-binding protein (1,25D-MARRS) is involved (Hii and Ferrante, 2016).

Several studies have confirmed the ability of vitamin D to affect cell proliferation and differentiation (Feldman et al., 2014; Fernandez-Barral et al., 2020a), and that it has an important role in decreasing the risk of developing multiple cancers ( $\mathrm{Wu}$ et al., 2019). The association between $1,25(\mathrm{OH})_{2} \mathrm{D}_{3}$ and cancer was initially detected in 1981, when inhibition of melanoma cells and differentiation induction of myeloid leukemic cells were reported (Abe et al., 1981; Colston et al., 1981). Since then, anticancer properties of vitamin D have been increasingly confirmed through in vitro and in vivo studies (Lappe et al., 2017; Jeon and Shin, 2018). Recent research has identified the crucial impact of vitamin D on carcinoma cells, especially in colon and breast cancers (Grant, 2020). In line with the antiproliferative effects of $1,25(\mathrm{OH})_{2} \mathrm{D}_{3}$, high VDR expression has also been shown in association with favorable prognosis (Feldman et al., 2014; Carlberg and Munoz, 2020). Although these previous studies have shown the positive role of VDR in patient prognosis, VDR has also been found to be associated with increased cancer risk (Zheng et al., 2017), indicating the controversial role of VDR. Thus, VDR may be a possible prognostic biomarker in patients. Furthermore, several findings support that vitamin D supplementation contributes to favorable prognosis ( $\mathrm{Ng}$ et al., 2019; Urashima et al., 2019; Yonaga et al., 2019), especially the prognosis improvement compared to those with treatment alone (Wesselink et al., 2020).

\section{ROLE OF VITAMIN D IN RADIOSENSITIVITY}

More recently, accumulating evidence has confirmed the anticancer role of vitamin $\mathrm{D}$ in several cancer models. In addition to the induction of differentiation and proliferation inhibition, the role of vitamin $\mathrm{D}$ as a magnifier of radiation response is emerging. Evaluation of combined therapy was performed in preclinical studies, showing synergistic or additive antitumor effectiveness. To date, the molecular mechanisms by which vitamin D potentiates the antitumor effects of RT are only partially known, and need further clarification. The antitumor actions of vitamin D are carried out through several mechanisms, 
such as induction of apoptosis, inhibition of proliferation, and suppression of angiogenesis. Additionally, vitamin D can also potentiate the antitumor effects of RT through different pathways. A summary of previous literature on the role of vitamin $\mathrm{D}$ to enhance radiation sensitization in cancer is presented in Figure 1.

\section{Apoptosis}

Cancer relapse occurs through multiple mechanisms, most of which are mediated by insufficient apoptosis. Increased DNA fragmentation induced by additive EB1089 in MDAMB-231 cells was associated with increased responsiveness to radiation (Sundaram and Gewirtz, 1999). Although the number of apoptotic cells triggered by radiation alone appeared to be minimal in MCF-7 cells, the rate and extent of cytotoxicity in irradiated cells were enhanced when combined with ILX23-7553 (vitamin D analog) (Chaudhry et al., 2001). It is important to emphasize that vitamin D3 and EB1089 promote the inactivation of BCL-2 (Simboli-Campbell et al., 1997), which is an anti-apoptotic protein. Additionally, high radiation doses have been correlated with more adverse events. In prostate cancer, vitamin D3 achieved equal therapeutic efficacy by inducing apoptosis along with marked attenuation of the radiation dose, thereby mitigating the side effects associated with a high radiation dose (Dunlap et al., 2003). In preclinical studies, these high-dose strategies show a weaker relationship with clinical RT, necessitating an experimental fractionation dose. The combination of ILX-23-7553 with fractionated radiation $(5 \times 2 \mathrm{~Gy}, 3$ days) demonstrated an advantage in inducing the apoptosis of MCF-7 cells; conversely, it appeared to have no impact on normal human fibroblasts, thus supporting the tumorspecific role of ILX-23-7553 (Polar et al., 2003). Similarly, a relationship between fractionated radiation and EB1089 has been reported in breast cancer: combination treatment led to a higher apoptotic rate than that with radiation alone and showed no detectable toxicity in normal breast epithelial cells or BJ fibroblast cells (DeMasters et al., 2004).

Moreover, it is known that radiation can directly induce cell death by DNA damage or indirectly by production of reactive oxygen species (ROS). When intrinsic resistance develops in tumor cells, ROS clearance is enhanced to ameliorate the oxidative stress. Xu et al. (2007) showed that RelB triggered by radiation resulted in the protection of irradiated cells, whereas vitamin D3 ablated this protection. As a member of the NF- $\kappa \mathrm{B}$ family, RelB can be inactivated by VDR-mediated transcriptional repression. Similarly, in breast cancer cells pre-treated with vitamin D3, sensitivity to radiation was increased accompanied with down-regulation of RelB (Mineva et al., 2009), again indicating that RelB was a target gene regulated by vitamin D in response to radiation.

\section{Autophagy}

As a source of cellular stress, radiation can also induce autophagy, which is a homeostasis mechanism for cellular stress and is mediated by a series of autophagy-related proteins. This process could also be influenced by vitamin D. Gewirtz (2014) first summarized the four faces of autophagy, which are the different types of autophagy that may play crucial roles in response to conventional therapies: (i) cytotoxic autophagy, (ii) cytoprotective autophagy, (iii) cytostatic autophagy, and (iv) non-protective autophagy.

\section{Cytotoxic Autophagy}

Demasters et al. (2006) indicated that autophagic cell death could be an important tumor cell elimination mechanism for combinatorial EB1089 and radiation in breast cancer. Cytotoxic autophagy is characterized by enhanced cell death, which is accompanied with earlier occurrence and greater extent of autophagosome, but no other apparent cell death type.

\section{Cytoprotective Autophagy}

Response to a single or combination treatment is not simply the result of a uniform type of autophagy, there is evidence that cytoprotective autophagy induced by radiation alone may be converted to cytotoxic autophagy when combined with vitamin D3 (Wilson et al., 2011). This further supports the view that dual functions of autophagy may be exhibited concomitantly. The cytoprotective form of autophagy is often considered as a mechanism of drug and radiation resistance in tumors (Ko et al., 2014). Consequently, autophagy inhibitors have been proposed to counteract the elevated cytoprotective autophagy induced by RT to improve radiosensitivity. Several studies have indicated that vitamin D3 shifted the autophagy type from cytoprotective to cytotoxic, which has been considered an autophagic switch (Wilson et al., 2011; Bristol et al., 2012).

\section{Cytostatic Autophagy}

Both cytotoxic and cytoprotective autophagy are closely related to the alteration of the autophagy flux level, whereas a cytostatic form of autophagy has been shown to exert beneficial antitumor effects on non-small cell lung carcinoma independent of the autophagy flux alteration. In a study by Sharma et al. (2014), EB1089 was revealed to increase radiation sensitization by inducing a growth-arrest status with no autophagy alteration or direct cell killing; interestingly, pharmacological inhibition or genetic silencing of autophagy rescued the tumor cells from the cytostatic status. EB1089 is possibly effective in switching the autophagy to cytostatic mode which appears to be involved in growth arrest. Therefore, autophagy primarily induced by radiation can be maintained, whereas the nature can be shifted to antitumor activity.

\section{Non-protective Autophagy}

Unlike cytoprotective autophagy, where autophagy inhibition results in an enhanced response to treatment, or cytotoxic and cytostatic autophagy where autophagy inhibition leads to reduced therapy efficiency, inhibition of non-protective autophagy shows no association with response to therapeutics. A study by Chakradeo et al. (2015) confirmed this finding by investigating whether cytoprotective autophagy induced by radiation in multiple cell lines was blocked by pharmacological inhibition or genetic silencing of autophagy genes. They found that inhibition of autophagy failed to influence the radiation sensitivity of p53 null cells, which seems to support the mysterious non-protective form of autophagy. 


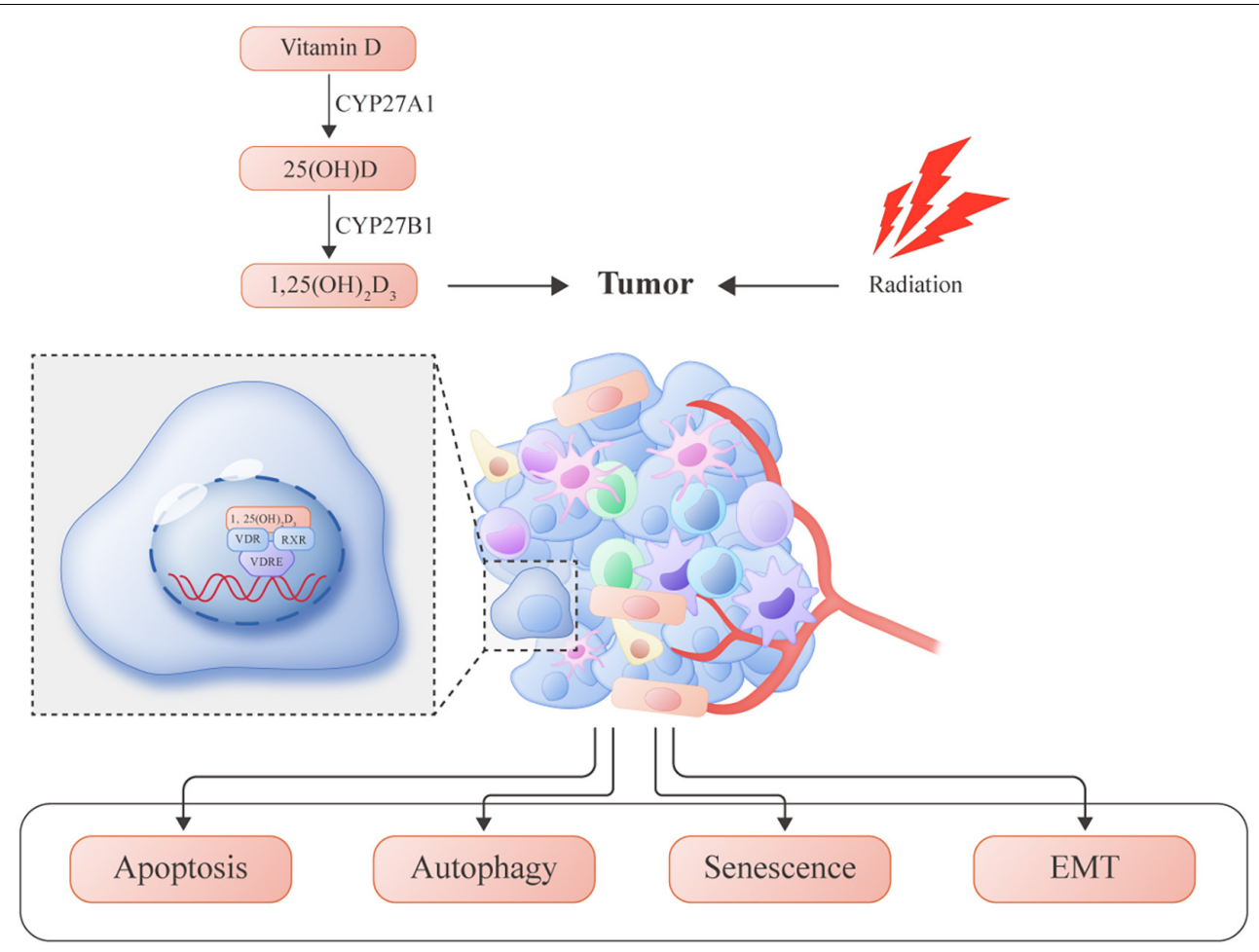

FIGURE 1 | Vitamin D-induced molecular mechanisms involved in enhancing radiosensitivity in several tumors.

\section{Senescence}

In a previous study, EB1089 was found to enhance cell apoptosis in response to radiation; the study also claimed that EB1089 had no perceptible effect on preventing senescence but only delayed the emergence of senescence (DeMasters et al., 2004). Similar studies on vitamin D3 mediated radiosensitivity also mentioned the occurrence of cell senescence (Demasters et al., 2006; Wilson et al., 2011).

\section{Therapy-Induced Senescence}

Traditionally, senescence was considered irreversible; however, recently, the focus has been on the capability to regain proliferation instead of quiescence in response to radiation. TIS was an accelerated form of senescence (or premature), different from the replicative senescence in aging cells. There is increasing evidence that low-dose radiation interferes with TIS (Yu et al., 2018). Under this condition, senescent cells can escape from direct damage due to RT and enter temporary dormancy; once re-activated, the surviving cells re-emerge from the dormant state and develop into a more aggressive phenotype (Rodier and Campisi, 2011). This is also termed "pseudosenescence" or "senescence-like arrest." Some clinical reports have demonstrated that patient prognosis was negatively correlated with the expression of senescence markers when exposed to radiation (Fischer et al., 2011).

\section{Senescence-Associated Secretory Phenotype}

Radiation influences not only irradiated cells but also the TME, or the so called SASP (Faget et al., 2019). SASP can influence the neighboring non-irradiated cells by releasing a series of proinflammatory chemokines and cytokines such as IL-1 $\beta$, IL-6, and CXCL1 into the surrounding environment (Acosta et al., 2013). Such molecules can hinder the success of RT. This bystander effect induced by radiation might be the mechanism by which a tumor treated with primary therapy becomes refractory to further treatment. This premise has been supported by Huang et al. (2014), who established a bystander model by treating non-irradiated cells with a conditioned medium acquired from irradiated senescent MDA-MB-231-2A cells. They demonstrated that the conditioned medium could lead to the invasion and migration of neighboring cells mediated by the JAK2-dependent AKT and STAT3 pathways. This non-targeted effect of radiation requires potential therapeutics for a better regulation between the target site and the surrounding microenvironment.

\section{Vitamin D and Senescence}

Studies on the elimination of TIS are underway for the prevention of disease relapse (Gorgoulis et al., 2019; Short et al., 2019). Notably, VDRE is a promoter of the gene encoding p21; thus, vitamin D3 could directly regulate p21 by binding to VDRE (Ylikomi et al., 2002). Elevated levels of IL-6 and IL-8 are associated with paracrine secretion in the SASP phenotype, and vitamin D3 has been proven to exert anti-inflammatory effects in prostate cancer through the inhibition of IL-6, IL-8, and TNF- $\alpha$ (Giangreco et al., 2015). Mechanistically, vitamin $\mathrm{D}$ was shown to inhibit the IL-6 production through the inactivation of p38MAPK (Nonn et al., 2006). These observations imply that vitamin D3 may be a potential senolytic that 
can eliminate senescence-related effects, thereby enhancing sensitization to radiation.

\section{Epithelial-to-Mesenchymal Transition}

EMT is a reversible process, which usually involves an initial loss of the differentiated phenotype to the migratory phenotype as circulating form in the bloodstream, and subsequent mesenchymal-epithelial transition (MET) for initial colonization leading to metastatic niches, thus generating intratumoral phenotypic heterogeneity (Angela Nieto, 2017). Usually, EMT is accompanied with diminished apoptosis and increased stemness, and both effects are linked to resistance to conventional therapies (Dongre and Weinberg, 2019). Data on colorectal cancer have shown that calcitriol significantly enhanced the therapeutic effects of radiation regulated by EMT (Findlay et al., 2014). In this study, Slug was involved, and overexpression of Slug in calcitriolsensitive cell lines abrogated the radiosensitization effect. DNA damage repair is a major regulator of treatment response and also involved in radioresistance. ZEB1 was reported to promote DNA damage repair (Zhang et al., 2014). Besides, the presence of Snail was correlated with decreased apoptosis mediated by $\mathrm{p} 53$ (Kurrey et al., 2009). Furthermore, upregulation of Slug by IR reversely contributed to inhibition of PUMA, thus decreasing apoptosis (Wu et al., 2005). These data establish EMT as a sensitization switch which regulates the treatment response, and harness of EMT related transcriptional factors may be a potential strategy for enhancing response to RT. Additionally, there is evidence that calcitriol can directly influence tumor-initiating cells (TICs, also known as cancer stem cells), which demonstrated that calcitriol in combination with radiation could inhibit spheroid formation more than either treatment alone; furthermore, this effect could be abolished by the overexpression of $\beta$-catenin (Jeong et al., 2015). It has been postulated that non-cancer stem cells are more sensitive to treatment, and EMT can directly characterize epithelial cells of the stem-cell properties, therefore, understanding the impact of calcitriol on EMT and CSCs might provide a novel insight into its effect on radiosensitivity.

Nevertheless, the scant molecular data have revealed that vitamin D may enhance the response to radiation at different levels. The reported molecular mechanisms involve the potentiation of existing apoptosis and the inhibition of protective autophagy. Moreover, the role of vitamin D in senescence and EMT transition requires further investigation. The available evidence strongly suggests that $1,25(\mathrm{OH})_{2} \mathrm{D}_{3}$ could be considered for combination therapy for cancer.

\section{RADIATION IMMUNITY}

As summarized above, vitamin D demonstrates a synergistic effect with radiation through various mechanisms. However, given the complexity of the direct impact of radiation on tumor cells and the indirect impact on the TME, it is worth noting the role that immune response plays in the response to RT. It has been traditionally thought that RT is an approach to suppress the immune system when harnessed for allogeneic transplantation (Rodier and Campisi, 2011). Recently, reactivation of the immune system, or the 6th $\mathrm{R}$ of radiobiology, has been proclaimed as the emerging target for RT (Fischer et al., 2011). RT participates in numerous steps of the immunological process (Figure 2). Therefore, the ultimate impact of vitamin D may be dependent, in part, on the radiation-induced TME, and the role that the immune system plays in the overall TME.

\section{RT Induced Immuno-Stimulation Immunogenic Cell Death}

Evidence shows that ICD is the dominant process responsible for the higher therapeutic efficacy of concurrent chemoradiotherapy than single chemotherapy (Formenti and Demaria, 2008). The effects of RT are far beyond tumor size reduction; RT converts the irradiated site into an immunogenic hub by releasing damage associated molecular patterns (DAMPs), the so-called "in situ vaccine" that contributes to the priming of the systemic immune response (Carvalho and Villar, 2018). Increasingly, evidence indicates that radiation-induced DAMPs can exert adjuvanticity by converting the "immune-cold" tumor into the "immunehot" tumor (Whiteside et al., 2016). "Cold" tumor normally does not respond to conventional therapies. This conversion relies on the ability of RT to induce primary tumor to be the immunogenic hub, thus significantly improving the effector $\mathrm{T}$ cell response (Zheng et al., 2016). A better appreciation of the intricate interaction between immune cold-to-hot conversion and radiotherapy is emerging (Galon and Bruni, 2019), which could shed light on tumors respond poorly to existing treatments. The mechanism of ICD includes CRT translocation to the dendritic cell (DC) surface promoting antigen presentation, release of HMGB1 from the dying cells to activate the Tolllike receptor 4 (TLR4) pathway, and ATP binding to the P2X7 receptor in DCs (Apetoh et al., 2007; Obeid et al., 2007; Ghiringhelli et al., 2009). Radiation can potentiate ICD through any of these three steps (Golden et al., 2014). Various DAMPs can be induced by radiation. HMGB1, as one of the DAMPs, has been shown to boost antigen presentation by DCs; other factors such as TLR4, which contributes to the binding of HMGB1 to DCs, are also triggered in response to radiation (Apetoh et al., 2007).

\section{Antigenicity}

Tumors with a higher antigen load have a greater tendency to induce the activation of naive $\mathrm{T}$ cells by DCs, leading to the possibility of low-immunogenic tumors inducing an immune response (Galluzzi et al., 2017). Following the release of tumor associated antigens (TAA) such as DAMPs, tumor-specific T cells are trafficked back to the tumor site, and the radiation-triggered immune response can therefore be amplified (individualized vaccination) (Vanpouille-Box et al., 2017). Radiation has been proven to lead to the upregulation of MHC-I, which further enhances the efficacy of antigen presentation (Reits et al., 2006). A similar effect has been observed in DCs, manifesting as improved maturation and recruitment of DCs to the irradiated site. The $\mathrm{T}$ cell function in response to RT was first described by Stone et al. (1979), who demonstrated that the attenuation of the radiation efficacy correlated with immune insufficiency. Experimental data have shown that the antitumor immune 


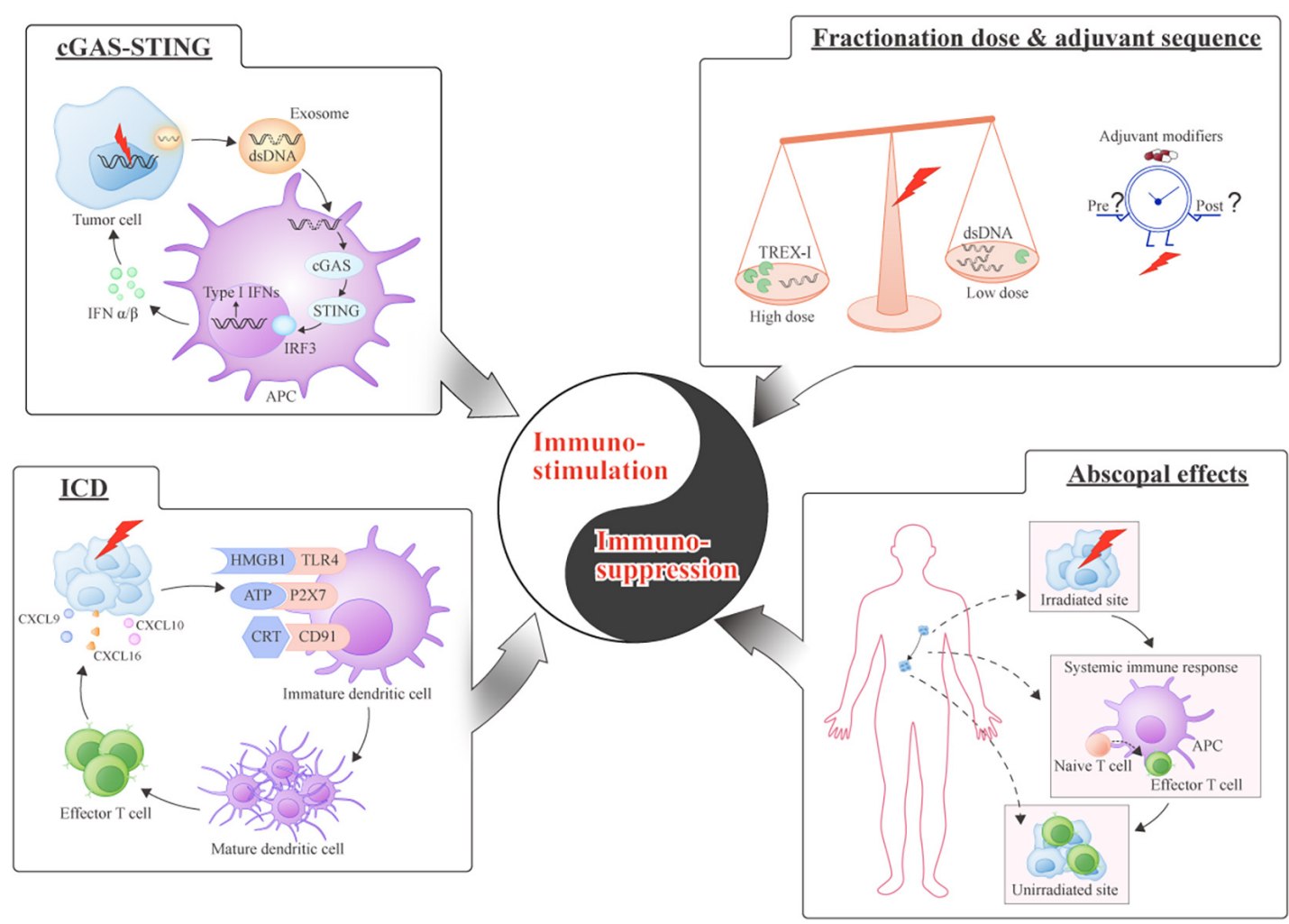

FIGURE 2 | Equilibrium between immuno-stimulation and immuno-suppression induced by radiation. Immuno-stimulation (Left): (cGAS-STING) cGAS-STING-mediated type I interferons (IFNs) are released by sensing double-stranded DNA (dsDNA) and contribute to the immune response; (Immunogenic cell death [ICD]) A schematic of the series of molecules binding to their receptors during immunogenic cell death. Immuno-suppression (Right): (Fractionation dose and sequence) The dose of RT influences immunomodulation through the production of Three-Prime Repair Exonuclease 1 (TREX1); the introduction of immune modifiers should be optimally timed; (Abscopal effects): The priming of antitumor immunity by local RT causes the distant tumor sites to shrink by activating systemic immune response.

effects of RT could be attributed to CD8+ T cell infiltration (Lee et al., 2009).

\section{Chemokines and Cytokines}

Specific chemokines and chemokine receptors are crucial for T-cell trafficking to the tumor site. For instance, irradiated tumors secrete C-X-C motif ligand 9 (CXCL9), CXCL10, and CXCL16, which bind to their receptors $\mathrm{C}-\mathrm{X}$ - $\mathrm{C}$ chemokine receptor type 3 (CXCR3) or CXCR6 expressed on T cells or T helper 1 cells $\left(\mathrm{T}_{\mathrm{H}} 1\right)$, and can facilitate the homing of CD8 T-cells to the irradiated site (McLaughlin et al., 2020). DNA damage has recently been identified to play a novel role in anti-tumor immunity induced by RT (Harding et al., 2017; Mackenzie et al., 2017), and the presence of double-stranded DNA (dsDNA), a recognized type I interferon (IFN-I) initiator, has been shown to elicit a tumorspecific T cell response (Deng et al., 2014; Vanpouille-Box et al., 2017). The cGAS-STING (cyclic GMP-AMP synthase-stimulator of interferon genes) pathway is of great significance as it is involved in dsDNA sensing and production of IFN-I during the radiation response (Deng et al., 2014; Harding et al., 2017; Mackenzie et al., 2017). The micronuclei derived from the damaged DNA can be transported by the nucleic acid sensors, cyclic GMP-AMP (cGAMP), to the STING dependent pathway and promote IFN-I production. Three-Prime Repair Exonuclease 1 (TREX1), upstream of cGAS, is a known exonuclease that can be transferred by exosome and has been shown to be associated with the degradation of dsDNA in irradiated cells (Diamond et al., 2018). Exosome is a particular form of extracellular vesicles with a size range of 40 to $160 \mathrm{~nm}$ in diameter and carries different types of cargoes inside (Kalluri and LeBleu, 2020). Previous evidence indicates that radioresistance is correlated with tumor derived exosomes (Ni et al., 2019). The most straightforward reply for how exosome respond to radiation is the alteration of its content because of altered TME induced by radiation (Diamond et al., 2018). The production of TREX1 is radiation dose-dependent and may lead to immune failure when receiving $\mathrm{RT}$ at a dose more than 12 Gy (Vanpouille-Box et al., 2017). Therefore, the commonly seen therapeutic resistance in response to high-dose RT may result from concentration-dependent TREX1, which can modulate cytosolic dsDNA and thus influence the immune response. It is important to understand that the tumor-cellintrinsic sensing remains unclear. There is evidence that caspase 9 (CASP9) signaling hijacked by the irradiated tumor cells can result in acquired resistance to radiation by the inhibition of innate DNA sensing (Han et al., 2020). When CASP9 was blocked using a pan-caspase inhibitor, a thousand-fold increase 
in IFN-I appeared in response to RT. Caspase appears to be involved in the immune response to radiation mediated by the innate DNA sensor.

\section{RT Induced Immuno-Suppression Immuno-Suppression}

Since cancer is commonly based on the equilibrium between proimmune and anti-immune effects in a degree sufficient to cause substantial cell death, T cells can induce successful immunization for achieving tumor elimination. An inhibitory TME often acts as a signal for immunosuppression, and this aberrant milieu influences the intrinsic properties of the surrounding cells. Specific immune suppressive cytokines are important for this milieu. Transforming growth factor- $\beta$ (TGF- $\beta$ ), which can be induced by radiation, has been shown to impair antigen-presentation by DCs and can impede effector $\mathrm{T}$ cell differentiation (Tauriello et al., 2018). A study has indicated that T cell-mediated tumor rejection was acquired only when combined with anti-TGF- $\beta$ (Vanpouille-Box et al., 2015). In addition, the remarkable myeloid-derived suppressor cells (MDSCs) induced by RT can also lead to immunosuppression mediated by TGF$\beta$ (Vatner and Formenti, 2015). Meanwhile, up-regulation of MDSCs in response to radiation is also associated with increased anti-programmed death-ligand 1 (PD-L1) expression on the cell surface of MDSCs (Dovedi et al., 2017). MDSCs can differentiate into mature macrophages, and there is evidence that radiation can cause the macrophage polarization into the M2 phenotype, thus attenuating the response to therapy (Tsai et al., 2007). Moreover, suppressive chemokines such as $\mathrm{C}-\mathrm{C}$ motif chemokine 2 (CCL2) or CCL5 released from irradiated cells can recruit MDSCs and regulatory CD4 T cells (Tregs) to the tumor site (Connolly et al., 2016). Intriguingly, although IFN-I derived from the cGAS-STING pathway plays an important role in the antitumor immune response induced by RT, long-term chronic interferon-driven basal interferon-stimulated gene (ISG) was also correlated with $\mathrm{T}$ cell dysfunction (McLaughlin et al., 2020). Thus, the dual target roles of IFN-I need further investigation for effectively mitigating immunosuppression.

\section{Abscopal Effect}

The ability of RT to inhibit tumor growth far from the irradiated site is called the abscopal effect (Formenti and Demaria, 2009). The link between the abscopal effect and systemic immunity was first reported by Demaria et al. (2004), who claimed that the antitumor immune response triggered by radiation can also elicit effective eradication of the non-irradiated tumor site. As an immunogenic hub, the field directly exposed to radiation sustains the in situ vaccine effect; however, this may be insufficient. The possible theories regarding how radiation can trigger the abscopal effect are based on the equilibrium between the immunostimulatory and immunosuppressive effects. As explained above, radiation not only has an immunostimulatory effect on the irradiated site but also promotes an immunosuppressive response in the surrounding environment. In a preclinical experiment, the abscopal effect was observed under blockade of immunosuppression (Levy et al., 2016), which supports the potential use of immune modifiers for this effect. Logically, TAAs play the role of mediators in the abscopal effect by shuttling outside the radiation field; however, when administered alone, radiation or immune checkpoint inhibitors (ICIs) did not inhibit growth in all the metastatic niches, suggesting that the antigenic overlap between the irradiated and non-irradiated sites was required to elicit an abscopal effect (Formenti et al., 2018). Activation of systemic antitumor immunity undergoes numerous processes including neoantigens releasing and priming of T cell infiltration. Notably, the abscopal effect is previously rare and single-site irradiation only shows some modest success, does not substantially increase the response rate (Luke et al., 2018). Therefore, we should rethink the importance of tumor heterogeneity. Radiation to multiple sites has been suggested to surmount this barrier and lead to optimal effectiveness of RT, which can be a meaningful strategy to prime systemic immune response (Brooks and Chang, 2019).

\section{Radiation Fractionation and Sequence}

Of note, the promotion or inhibition of the immune response triggered by radiation depends on various factors, such as the fractionation dose. A radiation dose of more than 7.5 Gy but not 5 Gy was revealed to stimulate the systemic immune response in a low immunogenic tumor (Stone et al., 1979), and a mathematical model appeared to allow the maximum immunity level in a range of 10-13 Gy (Lee et al., 2009). Conventional dose fractionation or single high-dose RT increases the amount of MDSCs, conversely, this can be reverted by hypofractionation (McLaughlin et al., 2020). There is evidence that $8 \mathrm{~Gy} \times 3$ fractions or $6 \mathrm{~Gy} \times 5$ fractions, but not a single high dose, can activate the immune response more intensively (Apetoh et al., 2007). Furthermore, a single dose of $20 \mathrm{~Gy}$ did not have a synergistic effect with additive immune modifiers. TREX1 induced by RT might help to elucidate the abrogation of the immune response (Nonn et al., 2006). Commonly, antitumor immune response with radiation alone has a limited effect, and optimal stimulation of the adaptive immunity requires the aid of ICIs. Recently, immune checkpoints, such as the programmed cell death protein 1 (PD1) or cytotoxic T lymphocyte-associated protein 4 (CTLA-4), as co-inhibitory receptors on $\mathrm{T}$ lymphocytes, have been selected as targets to reactivate $\mathrm{T}$ cell function (Harding et al., 2017). This application of ICIs can make the paradigm shift to RT and vice versa. Additionally, the increased antitumor activity also depends on whether the immune modifiers are administered, before, after, or concurrently with RT. This might be due to the functional mechanisms of modifiers to inhibit immunosuppression. For example, therapeutic benefit could be acquired only when antiPD-L1 was applied concomitantly with RT (Mackenzie et al., 2017). It seems that the effectiveness of anti-PD-L1 therapy depends on the upregulation of PD-L1 on the cell surface, which should be first activated by radiation.

A likely explanation for the mixed results is that a specific therapeutic window is needed for RT to remove the immune barriers when acting synergistically with immune adjuvants. Additional evidence on how conventional fractionation or hypofractionation influences the immune system should be acquired for harnessing the benefits of combination treatment. There is a very delicate balance between the immunostimulation 
and immunosuppression induced by RT; consequently, effective cancer treatment is determined by an optimal fractionation scheme combined with specific immune modifiers along with suitable timing.

\section{VITAMIN D AND IMMUNITY}

Although the crucial role of the TME during RT is widely accepted, studies on how the radiation-induced TME can be reprogrammed by adjuvants are scarce. Recent study has demonstrated that vitamin $\mathrm{D}$ can also modulate tumor stromal cells (Sherman et al., 2014), and the excellent review has summarized the effects of vitamin D on the TME (Wu et al., 2019). The primary association between vitamin $D$ and immunity is mainly thought to be based on energy metabolism and defense against infections. However, in recent years, vitamin $\mathrm{D}$ has been shown to be a multifaceted regulator of the immune system (Hanel and Carlberg, 2020). Vitamin D has been used for the treatment of autoimmune disorders by attenuation of the inflammatory immune response (Dimitrov et al., 2017), and it has also been shown to benefit organ transplant patients by inhibiting autoimmunity (Zhou et al., 2017). In fact, although vitamin D induces partial immunosuppression in normal tissues, the long-term effect of chronic inflammation control prevents tumorigenesis, allowing for the antitumor immunity induced by vitamin D.

Study has shown that the immune system can also affect vitamin D production (Liu et al., 2006). A high level of $25(\mathrm{OH}) \mathrm{D}_{3}$ in plasma led to a lower risk in the colorectal cancer subtype with an intense immune reaction, but had no effect on low degree reaction subtypes (Song et al., 2016). This further supports that sufficient immunity is necessary for vitamin D to exert its antitumor effect. Apart from kidney tubular cells, immune cells also express CYP27B1 and VDR, which reinforces the important role of vitamin $\mathrm{D}$ in regulating immune functions (Wei and Christakos, 2015; Christakos et al., 2016). Many types of immune cells such as DCs, CD4, and CD8 T cells expressing VDR (Lu et al., 2018) and CYP27B1 can produce the active metabolite $1,25(\mathrm{OH})_{2} \mathrm{D}_{3}$, which can maintain a healthy immune system (Barragan et al., 2015).

\section{Inflammation}

Not only the infiltrating immune cells but also cytokines and chemokines in the TME usually influence the tumor response to treatment (Diakos et al., 2014). Vitamin D regulates the inflammatory microenvironment through several mechanisms (Liu et al., 2018). NF- $\mathrm{B}$ plays an important role in regulating immune response (Miraghazadeh and Cook, 2018), and evidence supports the role of VDR antagonist in suppressing p65 activation (Tse et al., 2010). It was also found that vitamin D increased the infiltration of CD8+ $\mathrm{T}$ cells, and this was due to the suppression of IL-6 in the TME (Karkeni et al., 2019). Moreover, $1,25(\mathrm{OH})_{2} \mathrm{D}_{3}$ was effective in suppressing IL-8, which was based on the inhibition of NF- $\kappa$ B activation (Yang et al., 2018).

\section{Cancer-Associated Fibroblasts}

CAFs are a heterogeneous population of cells in the TME, derived from tumor cells or tumor stroma cells, and are usually involved in tumor progression and therapeutic resistance (Augsten, 2014). Therefore, a strategy to target the CAFs is necessary (Chen and Song, 2019). Recent data indicate that calcipotriol (VDR agonist) can enhance the therapeutic efficacy by reducing inflammation and fibrosis in pancreatic cancer (Sherman et al., 2014). In line with these data, analyses of patients have reported that high VDR expression in CAFs is associated with better prognosis (FerrerMayorga et al., 2017). These findings are clinically relevant, which indicates that VDR agonists can exert antitumor actions on tumor stromal cells and patients in carcinoma VDR-negative status may still benefit from vitamin $\mathrm{D}$ treatment. In recent years, recognition of the crucial role played by exosome in cancer has led to the novel insight for selectively targeting cancer cells (Knox et al., 2020). In this context, a study (Kong et al., 2019) reported that vitamin $\mathrm{D}$ decreased the amount of exosomes secreted by the CAFs and thus inhibited the tumor promoter miR-10a-5p in pancreatic cancer.

\section{Cancer Stem Cells}

CSCs are a subpopulation of cells characterized by selfrenewal due to the accumulation of genetic and epigenetic alterations, and possibly make an important contribution to therapeutic resistance. Moreover, inhibition of CSCs by vitamin $\mathrm{D}$ has been described in prostate and breast malignancies as a promising treatment strategy (So and Suh, 2015). 1,25(OH $)_{2} \mathrm{D}_{3}$ has been found to reduce sphere formation in breast cancer, with downregulation of stem cell markers and NOTCH pathway genes (Shan et al., 2017). Organoids have been proposed to represent the in vivo situation, as three-dimensional structures generated by primary normal or cancer stem cells isolated from the patients. On the one hand, $1,25(\mathrm{OH})_{2} \mathrm{D}_{3}$ can induce cell differentiation in colon tumor organoids and lead to a more epithelial phenotype (Fernandez-Barral et al., 2020b). On the other hand, $1,25(\mathrm{OH})_{2} \mathrm{D}_{3}$ upregulates stemness-related genes and downregulates differentiation genes in normal rectum organoids (Costales-Carrera et al., 2020). These results demonstrate the different roles of vitamin D in normal stem cells and colon CSCs. Recently, it has been demonstrated that vitamin D induced significant downregulation of stemness-related genes compared to imatinib alone, indicating the apparent amplified function of vitamin D on CSCs (Kotlarz et al., 2019). Likewise, reduction of MCF-7 stem cell subpopulation can be induced by VDR overexpression, which elevates sensitivity to tamoxifen (Zheng et al., 2018).

The above data clearly demonstrate that $1,25(\mathrm{OH})_{2} \mathrm{D}_{3}$ can suppress tumor progression by modulating the TME. Initially, it has been shown that immune cells and tumor stromal cells express VDR, which contributes to $1,25(\mathrm{OH})_{2} \mathrm{D}_{3}$ responsiveness. Supporting this, vitamin D correlates inversely with the CAFs in the surrounding TME. In addition, the inhibition of CSCs is probably also a consequence of TME regulation by $1,25(\mathrm{OH})_{2} \mathrm{D}_{3}$. Similar functional effects were observed on the novel three-dimensional structures of organoids. Taken together, vitamin $\mathrm{D}$ modulates the TME in diverse ways, which strongly indicates the multi-level anticancer actions of vitamin $\mathrm{D}$ in various cancers. 


\section{FUTURE PERSPECTIVES}

This review aimed to bring together two different fields, namely, vitamin $\mathrm{D}$ and radiation, which have rarely been linked before. We used the TME as the bridge between the two fields. However, further investigation is required before we can fully elucidate the impact of vitamin D on radiation. Notable evidence reported in previous studies has highlighted the importance of the TME in the treatment response of cancer. Molecular scenarios induced by radiation in cancer also demonstrate the remarkable functions of the TME. We hypothesize that, if the immunosuppression caused by radiation can be weakened or subtracted by vitamin $\mathrm{D}$, the equilibrium will be broken and immunostimulation will be in dominancy. Supporting this, suitable vitamin $\mathrm{D}$ intervention in combination with radiation can induce an antiproliferative additive effect, and this effect of RT may be derived from not only directly causing cancer cell death but also indirectly reprogramming the TME. This may widen the perspective on vitamin $\mathrm{D}$ with regard to its immune modulatory role, which is essential for the treatment of autoimmune disorders. Overall, radiation therapy is complex with the involvement of intricate immune modulation and multiple types of cancer cell death. Additional research is needed to elucidate the underlying mechanisms and the potential utility of vitamin D in RT.

Nonetheless, more investigations are needed to confirm whether there is existing resistance to vitamin D itself, accompanied with the detection of a vitamin D responsedependent biomarker, which could facilitate the selection of patients with a higher likelihood of response to vitamin D, and decide the biologically optimal dose of vitamin $\mathrm{D}$ for

\section{REFERENCES}

Abe, E., Miyaura, C., Sakagami, H., Takeda, M., Konno, K., Yamazaki, T., et al. (1981). Differentiation of mouse myeloid leukemia cells induced by 1 alpha,25dihydroxyvitamin D3. Proc. Natl. Acad. Sci. U.S.A. 78, 4990-4994. doi: 10.1073/ pnas.78.8.4990

Acosta, J. C., Banito, A., Wuestefeld, T., Georgilis, A., Janich, P., Morton, J. P., et al. (2013). A complex secretory program orchestrated by the inflammasome controls paracrine senescence. Nat. Cell Biol. 15, 978-990. doi: 10.1038/ ncb 2784

Amrein, K., Scherkl, M., Hoffmann, M., Neuwersch-Sommeregger, S., Koestenberger, M., Berisha, A. T., et al. (2020). Vitamin D deficiency 2.0: an update on the current status worldwide. Eur. J. Clin. Nut. 74, 1498-1513. doi: 10.1038/s41430-020-0558-y

Angela Nieto, M. (2017). Context-specific roles of EMT programmes in cancer cell dissemination. Nat. Cell Biol. 19, 416-418. doi: 10.1038/ncb3520

Apetoh, L., Ghiringhelli, F., Tesniere, A., Obeid, M., Ortiz, C., Criollo, A., et al. (2007). Toll-like receptor 4-dependent contribution of the immune system to anticancer chemotherapy and radiotherapy. Nat. Med. 13, 1050-1059.

Augsten, M. (2014). Cancer-associated fibroblasts as another polarized cell type of the tumor microenvironment. Front. Oncol. 4:62. doi: 10.3389/fonc.2014.00062

Barragan, M., Good, M., and Kolls, J. K. (2015). Regulation of dendritic cell function by Vitamin D. Nutrients 7, 8127-8151. doi: 10.3390/nu7095383

Bikle, D. D. (2014). Vitamin D Metabolism, mechanism of action, and clinical applications. Chem. Biol. 21, 319-329. doi: 10.1016/j.chembiol.2013.12.016

Bischoff-Ferrari, H. A., Dawson-Hughes, B., Orav, J., Staehelin, H. B., Meyer, O. W., Theiler, R., et al. (2016). Monthly high-dose Vitamin D treatment for achieving maximum health benefit. Is there a scheme to satisfy the target doses by controlling the local concentration of calcitriol? For greater benefits, the development of VDR agonists is recommended, which is deemed to acquire the equieffective but less hypercalcaemia effect. The timing of vitamin D initiation during combination therapy is another important issue. For best regimen, whether the agent should be supplemented continuously or not? Does radiation alter vitamin D metabolism indirectly? These explorations may contribute to the discovery of potential cost-effective and efficient agent for combination treatment with conventional therapeutics.

\section{AUTHOR CONTRIBUTIONS}

GC conceptualized and supervised the conception of the manuscript. GC and XY coordinated and performed the literature search with $\mathrm{BL}, \mathrm{NZ}$, and $\mathrm{QW}$ contribution. $\mathrm{XY}$ and GC designed and performed figures, and wrote the manuscript with important inputs from all authors. All authors reviewed and agreed with the content of the manuscript.

\section{FUNDING}

This work was supported by grants from the National Natural Science Foundation of China (grant numbers 82073331 and 82003208), the Jilin Province Science and Technology Development Plan Project (grant number 20200201599JC), and the Project of Science and Technology Department of Jilin Province (grant number 20190303151SF).

the prevention of functional decline A randomized clinical trial. Jama Int. Med. 176, 175-183. doi: 10.1001/jamainternmed.2015.7148

Bristol, M. L., Di, X., Beckman, M. J., Wilson, E. N., Henderson, S. C., Maiti, A., et al. (2012). Dual functions of autophagy in the response of breast tumor cells to radiation Cytoprotective autophagy with radiation alone and cytotoxic autophagy in radiosensitization by vitamin D-3. Autophagy 8, 739-753. doi: 10.4161/auto.19313

Brooks, E. D., and Chang, J. Y. (2019). Time to abandon single-site irradiation for inducing abscopal effects. Nat. Rev. Clin. Oncol. 16, 123-135. doi: 10.1038/ s41571-018-0119-7

Carlberg, C., and Munoz, A. (2020). An update on vitamin D signaling and cancer. Semin. Cancer Biol. S1044-S1579, 30114-30110.

Carvalho, H. D. A., and Villar, R. C. (2018). Radiotherapy and immune response: the systemic effects of a local treatment. Clinics 73:e557s.

Chakradeo, S., Sharma, K., Alhaddad, A., Bakhshwin, D., Le, N., Harada, H., et al. (2015). Yet another function of p53-the switch that determines whether radiation-induced autophagy will be cytoprotective or nonprotective: implications for autophagy inhibition as a therapeutic strategy. Mol. Pharmacol. 87, 803-814. doi: $10.1124 / \mathrm{mol} .114 .095273$

Charoenngam, N., and Holick, M. F. (2020). Immunologic effects of Vitamin D on human health and disease. Nutrients 12:2097. doi: 10.3390/nu12072097

Chaudhry, M., Sundaram, S., Gennings, C., Carter, H., and Gewirtz, D. A. (2001). The vitamin D-3 analog, ILX-23-7553, enhances the response to Adriamycin and irradiation in MCF-7 breast tumor cells. Cancer Chemother. Pharmacol. 47, 429-436. doi: 10.1007/s002800000251

Chen, X., and Song, E. (2019). Turning foes to friends: targeting cancer-associated fibroblasts. Nat. Rev. Drug Discov. 18, 99-115. doi: 10.1038/s41573-018-0004-1 
Chen, Y.-P., Chan, A. T. C., Quynh-Thu, L., Blanchard, P., Sun, Y., and Ma, J. (2019). Nasopharyngeal carcinoma. Lancet 394, 64-80.

Christakos, S., Dhawan, P., Verstuyf, A., Verlinden, L., and Carmeliet, G. (2016). Vitamin D: metabolism, molecular mechanism of action, and pleiotropic effects. Physiol. Rev. 96, 365-408. doi: 10.1152/physrev.00014.2015

Cohen, P. A., Jhingran, A., Oaknin, A., and Denny, L. (2019). Cervical cancer. Lancet 393, 169-182.

Colston, K., Colston, M. J., and Feldman, D. (1981). 1,25-dihydroxyvitamin D3 and malignant melanoma: the presence of receptors and inhibition of cell growth in culture. Endocrinology 108, 1083-1086. doi: 10.1210/endo-108-3-1083

Connolly, K. A., Belt, B. A., Figueroa, N. M., Murthy, A., Patel, A., Kim, M., et al. (2016). Increasing the efficacy of radiotherapy by modulating the CCR2/CCR5 chemokine axes. Oncotarget 7, 86522-86535. doi: 10.18632/oncotarget.13287

Costales-Carrera, A., Fernandez-Barral, A., Bustamante-Madrid, P., Dominguez, O., Guerra-Pastrian, L., Cantero, R., et al. (2020). Comparative study of organoids from patient-derived normal and tumor colon and rectal tissue. Cancers 12:2302. doi: 10.3390/cancers12082302

Dekker, E., Tanis, P. J., Vleugels, J. L. A., Kasi, P. M., and Wallace, M. B. (2019). Colorectal cancer. Lancet 394, 1467-1480.

Demaria, S., Ng, B., Devitt, M. L., Babb, J. S., Kawashima, N., Liebes, L., et al. (2004). Ionizing radiation inhibition of distant untreated tumors (abscopal effect) is immune mediated. Int. J. Radiat. Oncol. Biol. Phys. 58, 862-870. doi: 10.1016/j.ijrobp.2003.09.012

Demasters, G., Di, X., Newsham, I., Shiu, R., and Gewirtz, D. A. (2006). Potentiation of radiation sensitivity in breast tumor cells by the vitamin D3 analogue, EB 1089, through promotion of autophagy and interference with proliferative recovery. Mol. Cancer Ther. 5, 2786-2797. doi: 10.1158/15357163.mct-06-0316

DeMasters, G. A., Gupta, M. S., Jones, K. R., Cabot, M., Wang, H., Gennings, C., et al. (2004). Potentiation of cell killing by fractionated radiation and suppression of proliferative recovery in MCF-7 breast tumor cells by the Vitamin D3 analog EB 1089. J. Steroid. Biochem. Mol. Biol. 92, 365-374. doi: 10.1016/j.jsbmb.2004.07.011

Deng, L., Liang, H., Xu, M., Yang, X., Burnette, B., Arina, A., et al. (2014). STING-Dependent cytosolic DNA sensing promotes radiation-induced Type I interferon-dependent antitumor immunity in immunogenic tumors. Immunity 41, 843-852. doi: 10.1016/j.immuni.2014.10.019

Diakos, C. I., Charles, K. A., McMillan, D. C., and Clarke, S. J. (2014). Cancerrelated inflammation and treatment effectiveness. Lancet Oncol. 15, E493E503.

Diamond, J. M., Vanpouille-Box, C., Spada, S., Rudqvist, N. P., Chapman, J. R., Ueberheide, B. M., et al. (2018). Exosomes Shuttle TREX1-Sensitive IFNStimulatory dsDNA from irradiated cancer cells to DCs. Cancer Immunol. Res. 6, 910-920. doi: 10.1158/2326-6066.cir-17-0581

Dimitrov, V., Bouttier, M., Boukhaled, G., Salehi-Tabar, R., Avramescu, R. G., Memari, B., et al. (2017). Hormonal vitamin D up-regulates tissue-specific PDL1 and PD-L2 surface glycoprotein expression in humans but not mice. J. Biol. Chem. 292, 20657-20668. doi: 10.1074/jbc.m117.793885

Dongre, A., and Weinberg, R. A. (2019). New insights into the mechanisms of epithelial-mesenchymal transition and implications for cancer. Nat. Rev. Mol. Cell Biol. 20, 69-84. doi: 10.1038/s41580-018-0080-4

Dovedi, S. J., Cheadle, E. J., Popple, A. L., Poon, E., Morrow, M., Stewart, R., et al. (2017). Fractionated radiation therapy stimulates antitumor immunity mediated by both resident and infiltrating polyclonal T-cell populations when combined with PD-1 blockade. Clin. Cancer Res. 23, 5514-5526. doi: 10.1158/ 1078-0432.ccr-16-1673

Dunlap, N., Schwartz, G. G., Eads, D., Cramer, S. D., Sherk, A. B., John, V., et al. (2003). 1alpha,25-dihydroxyvitamin $\mathrm{D}$ (3) (calcitriol) and its analogue, 19-norlalpha, $25(\mathrm{OH})(2) \mathrm{D}(2)$, potentiate the effects of ionising radiation on human prostate cancer cells. Br. J. Cancer 89, 746-753. doi: 10.1038/sj.bjc.6601161

Faget, D. V., Ren, Q., and Stewart, S. A. (2019). Unmasking senescence: contextdependent effects of SASP in cancer. Nat. Rev. Cancer 19, 439-453. doi: 10. 1038/s41568-019-0156-2

Feldman, D., Krishnan, A. V., Swami, S., Giovannucci, E., and Feldman, B. J. (2014). The role of vitamin D in reducing cancer risk and progression. Nat. Rev. Cancer 14, 342-357. doi: 10.1038/nrc3691

Fernandez-Barral, A., Bustamante-Madrid, P., Ferrer-Mayorga, G., Barbachano, A., Larriba, M. J., and Munoz, A. (2020a). Vitamin D effects on cell differentiation and stemness in cancer. Cancers 12:2413. doi: 10.3390/ cancers 12092413

Fernandez-Barral, A., Costales-Carrer, A., Buira, S. P., Jung, P., Ferrer-Mayorga, G., Larriba, M. J., et al. (2020b). Vitamin D differentially regulates colon stem cells in patient-derived normal and tumor organoids. FEBS J. 287, 53-72. doi: $10.1111 /$ febs. 14998

Ferrer-Mayorga, G., Gomez-Lopez, G., Barbachano, A., Fernandez-Barral, A., Pena, C., Pisano, D. G., et al. (2017). Vitamin D receptor expression and associated gene signature in tumor stromal fibroblasts predict clinical outcome in colorectal cancer. Gut 66, 1449-1462. doi: 10.1136/gutjnl-2015-310977

Findlay, V. J., Moretz, R. E., Wang, C., Vaena, S. G., Bandurraga, S. G., Ashenafi, M., et al. (2014). Slug expression inhibits calcitriol-mediated sensitivity to radiation in colorectal cancer. Mol. Carcinog. 53(Suppl. 1), E130-E139.

Fischer, C. A., Jung, M., Zlobec, I., Green, E., Storck, C., Tornillo, L., et al. (2011). Co-overexpression Of P21 And Ki-67 in head and neck squamous cell carcinoma relative to a significantly poor prognosis. Head Neck 33, 267-273. doi: 10.1002/hed.21440

Formenti, S. C., and Demaria, S. (2008). Effects of chemoradiation on tumorhost interactions: the immunologic side. J. Clin. Oncol. 26, 1562-1563. doi: 10.1200/jco.2007.15.5499

Formenti, S. C., and Demaria, S. (2009). Systemic effects of local radiotherapy. Lancet Oncol. 10, 718-726. doi: 10.1016/s1470-2045(09)70082-8

Formenti, S. C., Rudqvist, N.-P., Golden, E., Cooper, B., Wennerberg, E., Lhuillier, C., et al. (2018). Radiotherapy induces responses of lung cancer to CTLA-4 blockade. Nat. Med. 24, 1845-1851. doi: 10.1038/s41591-018-0232-2

Galluzzi, L., Buque, A., Kepp, O., Zitvogel, L., and Kroemer, G. (2017). Immunogenic cell death in cancer and infectious disease. Nat. Rev. Immunol. 17, 97-111. doi: 10.1038/nri.2016.107

Galon, J., and Bruni, D. (2019). Approaches to treat immune hot, altered and cold tumors with combination immunotherapies. Nat. Rev. Drug Discov. 18, 197-218. doi: 10.1038/s41573-018-0007-y

Gewirtz, D. A. (2014). The four faces of autophagy: implications for cancer therapy. Cancer Res. 74, 647-651. doi: 10.1158/0008-5472.can-13-2966

Ghiringhelli, F., Apetoh, L., Tesniere, A., Aymeric, L., Ma, Y., Ortiz, C., et al. (2009). Activation of the NLRP3 inflammasome in dendritic cells induces IL1 beta-dependent adaptive immunity against tumors. Nat. Med. 15, 1170-1178. doi: $10.1038 / \mathrm{nm} .2028$

Giangreco, A. A., Dambal, S., Wagner, D., Van der Kwast, T., Vieth, R., Prins, G. S., et al. (2015). Differential expression and regulation of vitamin D hydroxylases and inflammatory genes in prostate stroma and epithelium by 1,25-dihydroxyvitamin D in men with prostate cancer and an in vitro model. J. Steroid Biochem. Mol. Biol. 148, 156-165. doi: 10.1016/j.jsbmb.2014.10.004

Golden, E. B., Frances, D., Pellicciotta, I., Demaria, S., Barcellos-Hoff, M. H., and Formenti, S. C. (2014). Radiation fosters dose-dependent and chemotherapyinduced immunogenic cell death. Oncoimmunology 3:e28518. doi: 10.4161/ onci. 28518

Gorgoulis, V., Adams, P. D., Alimonti, A., Bennett, D. C., Bischof, O., Bishop, C., et al. (2019). Cellular senescence: defining a path forward. Cell 179, 813-827. doi: 10.1016/j.cell.2019.10.005

Grant, W. B. (2020). Review of recent advances in understanding the role of Vitamin D in reducing cancer risk: breast, colorectal, prostate, and overall cancer. Anticancer Res. 40, 491-499. doi: 10.21873/anticanres.13977

Han, C., Liu, Z., Zhang, Y., Shen, A., Dong, C., Zhang, A., et al. (2020). Tumor cells suppress radiation-induced immunity by hijacking caspase 9 signaling. Nat. Immunol. 21, 546-554. doi: 10.1038/s41590-020-0641-5

Hanel, A., and Carlberg, C. (2020). Vitamin D and evolution: pharmacologic implications. Biochem. Pharmacol. 173:113595. doi: 10.1016/j.bcp.2019. 07.024

Harding, S. M., Benci, J. L., Irianto, J., Discher, D. E., Minn, A. J., and Reenberg, R. A. G. (2017). Mitotic progression following DNA damage enables pattern recognition within micronuclei. Nature 548, 466-470. doi: 10.1038/ nature 23470

Hii, C. S., and Ferrante, A. (2016). The non-genomic actions of Vitamin D. Nutrients 8:135. doi: 10.3390/nu8030135

Huang, Y. H., Yang, P. M., Chuah, Q. Y., Lee, Y. J., Hsieh, Y. F., Peng, C. W., et al. (2014). Autophagy promotes radiation-induced senescence but inhibits bystander effects in human breast cancer cells. Autophagy 10, 1212-1228. doi: 10.4161 /auto. 28772 
Jeon, S.-M., and Shin, E.-A. (2018). Exploring vitamin D metabolism and function in cancer. Exp. Mol. Med. 50:20.

Jeong, Y., Swami, S., Krishnan, A. V., Williams, J. D., Martin, S., Horst, R. L., et al. (2015). Inhibition of mouse breast tumor-initiating cells by calcitriol and dietary Vitamin D. Mol. Cancer Ther. 14, 1951-1961. doi: 10.1158/1535-7163. mct-15-0066

Jones, G. (2010). Vitamin D analogs. endocrinology and metabolism. Clin. North Am. 39, 447-472. doi: 10.1016/j.ecl.2010.02.003

Jones, G., Prosser, D. E., and Kaufmann, M. (2012). 25-Hydroxyvitamin D-24hydroxylase (CYP24A1): its important role in the degradation of vitamin D. Arch. Biochem. Biophys. 523, 9-18. doi: 10.1016/j.abb.2011.11.003

Jones, G., Prosser, D. E., and Kaufmann, M. (2014). Thematic review series: fat-soluble Vitamins: Vitamin D Cytochrome P450-mediated metabolism of vitamin D. J. Lipid Res. 55, 13-31.

Kalluri, R., and LeBleu, V. S. (2020). The biology, function, and biomedical applications of exosomes. Science 367:eaau6977. doi: 10.1126/science.aau6977

Karkeni, E., Morin, S. O., Tayeh, B. B., Goubard, A., Josselin, E., Castellano, R., et al. (2019). Vitamin D controls tumor growth and CD8+T cell infiltration in breast cancer. Front. Immunol. 10:1307. doi: 10.3389/fimmu.2019.01307

Keum, N., Lee, D. H., Greenwood, D. C., Manson, J. E., and Giovannucci, E. (2019). Vitamin D supplementation and total cancer incidence and mortality: a meta-analysis of randomized controlled trials. Ann. Oncol. 30, 733-743. doi: 10.1093/annonc/mdz059

Knox, M. C., Ni, J., Bece, A., Bucci, J., Chin, Y., Graham, P. H., et al. (2020). A clinician's guide to cancer-derived exosomes: immune interactions and therapeutic implications. Front. Immunol. 11:1612. doi: 10.3389/fimmu.2020. 01612

Ko, A., Kanehisa, A., Martins, I., Senovilla, L., Chargari, C., Dugue, D., et al. (2014). Autophagy inhibition radiosensitizes in vitro, yet reduces radioresponses in vivo due to deficient immunogenic signalling. Cell Death Differ. 21, 92-99. doi: $10.1038 /$ cdd.2013.124

Kong, F., Li, L., Wang, G., Deng, X., Li, Z., and Kong, X. (2019). VDR signaling inhibits cancer-associated-fibroblasts' release of exosomal miR-10a-5p and limits their supportive effects on pancreatic cancer cells. Gut 68, 950-951. doi: 10.1136/gutjnl-2018-316627

Kotlarz, A., Przybyszewska, M., Swoboda, P., Neska, J., Miloszewska, J., Grygorowicz, M. A., et al. (2019). Imatinib inhibits the regrowth of human colon cancer cells after treatment with 5-FU and cooperates with vitamin D analogue PRI-2191 in the downregulation of expression of sternness-related genes in 5-FU refractory cells. J. Steroid Biochem. Mol. Biol. 189, 48-62. doi: 10.1016/j.jsbmb.2019.02.003

Kurrey, N. K., Jalgaonkar, S. P., Joglekar, A. V., Ghanate, A. D., Chaskar, P. D., Doiphode, R. Y., et al. (2009). Snail and slug mediate radioresistance and chemoresistance by antagonizing p53-Mediated apoptosis and acquiring a stem-like phenotype in ovarian cancer cells. Stem Cells 27, 2059-2068. doi: $10.1002 /$ stem. 154

Lappe, J., Garland, C., and Gorham, E. (2017). Vitamin D supplementation and cancer risk reply. JAMA J. Am. Med. Assoc. 318, 299-300. doi: 10.1001/jama. 2017.7833

Lee, Y., Auh, S. L., Wang, Y., Burnette, B., Wang, Y., Meng, Y., et al. (2009). Therapeutic effects of ablative radiation on local tumor require CD8+ T cells: changing strategies for cancer treatment. Blood 114, 589-595. doi: 10.1182/ blood-2009-02-206870

Levy, A., Chargari, C., Marabelle, A., Perfettini, J.-L., Magne, N., and Deutsch, E. (2016). Can immunostimulatory agents enhance the abscopal effect of radiotherapy? Eur. J. Cancer 62, 36-45. doi: 10.1016/j.ejca.2016.03.067

Liu, P. T., Stenger, S., Li, H. Y., Wenzel, L., Tan, B. H., Krutzik, S. R., et al. (2006). Toll-like receptor triggering of a vitamin D-mediated human antimicrobial response. Science 311, 1770-1773. doi: 10.1126/science.1123933

Liu, W., Zhang, L., Xu, H.-J., Li, Y., Hu, C.-M., Yang, J.-Y., et al. (2018). The antiinflammatory effects of Vitamin D in tumorigenesis. Int. J. Mol. Sci. 19:2736. doi: $10.3390 /$ ijms 19092736

Lu, M., Taylor, B. V., and Korner, H. (2018). Genomic effects of the Vitamin D receptor: potentially the link between Vitamin D, immune cells, and multiple sclerosis. Front. Immunol. 9:477. doi: 10.3389/fimmu.2018.00477

Luke, J. J., Lemons, J. M., Karrison, T. G., Pitroda, S. P., Melotek, J. M., Zha, Y., et al. (2018). Safety and clinical activity of pembrolizumab and multisite stereotactic body radiotherapy in patients with advanced solid tumors. J. Clin. Oncol. 36, 1611-1618. doi: 10.1200/jco.2017.76.2229

Mackenzie, K. J., Carroll, P., Martin, C.-A., Murina, O., Fluteau, A., Impson, D. J. S., et al. (2017). cGAS surveillance of micronuclei links genome instability to innate immunity. Nature 548, 461-465. doi: 10.1038/nature23449

Markotic, A., Langer, S., Kelava, T., Vucic, K., Turcic, P., Tokic, T., et al. (2019). Higher post-operative serum Vitamin D Level is associated with better survival outcome in colorectal cancer patients. Nutr. Cancer Int. J. 71, 1078-1085. doi: 10.1080/01635581.2019.1597135

Maurya, V. K., Bashir, K., and Aggarwal, M. (2020). Vitamin D microencapsulation and fortification: trends and technologies. J. Steroid Biochem. Mol. Biol. 196:105489. doi: 10.1016/j.jsbmb.2019.105489

McLaughlin, M., Patin, E. C., Pedersen, M., Wilkins, A., Dillon, M. T., Melcher, A. A., et al. (2020). Inflammatory microenvironment remodelling by tumor cells after radiotherapy. Nat. Rev. Cancer 20, 203-217. doi: 10.1038/s41568020-0246-1

Mineva, N. D., Wang, X., Yang, S., Ying, H., Xiao, Z. X., Holick, M. F., et al. (2009). Inhibition of RelB by 1,25-dihydroxyvitamin $\mathrm{D} 3$ promotes sensitivity of breast cancer cells to radiation. J. Cell Physiol. 220, 593-599. doi: 10.1002/jcp.21765

Miraghazadeh, B., and Cook, M. C. (2018). Nuclear Factor-kappaB in autoimmunity: man and mouse. Front. Immunol. 9:613. doi: 10.3389/fimmu. 2018.00613

Ng, K., Nimeiri, H. S., McCleary, N. J., Abrams, T. A., Yurgelun, M. B., Cleary, J. M., et al. (2019). Effect of high-dose vs Standard-Dose Vitamin D-3 supplementation on progression-free survival among patients with advanced or metastatic colorectal cancer the SUNSHINE randomized clinical trial. JAMA J. Am. Med. Assoc. 321, 1370-1379. doi: 10.1001/jama.2019.2402

Ni, J., Bucci, J., Malouf, D., Knox, M., Graham, P., and Li, Y. (2019). Exosomes in cancer radioresistance. Front. Oncol. 9:869. doi: 10.3389/fonc.2019.00869

Nonn, L., Peng, L. H., Feldman, D., and Peehl, D. M. (2006). Inhibition of p38 by vitamin $D$ reduces interleukin- 6 production in normal prostate cells via mitogen-activated protein kinase phosphatase 5: implications for prostate cancer prevention by vitamin D. Cancer Res. 66, 4516-4524. doi: 10.1158/00085472.can-05-3796

Obeid, M., Tesniere, A., Ghiringhelli, F., Fimia, G. M., Apetoh, L., Perfettini, J.-L., et al. (2007). Calreticulin exposure dictates the immunogenicity of cancer cell death. Nat. Med. 13, 54-61. doi: 10.1038/nm1523

Polar, M. K., Gennings, C., Park, M., Gupta, M. S., and Gewirtz, D. A. (2003). Effect of the vitamin D3 analog ILX 23-7553 on apoptosis and sensitivity to fractionated radiation in breast tumor cells and normal human fibroblasts. Cancer Chemother. Pharmacol. 51, 415-421. doi: 10.1007/s00280-0030606-z

Ramakrishnan, S., Steck, S. E., Arab, L., Zhang, H., Bensen, J. T., Fontham, E. T. H., et al. (2019). Association among plasma $1,25(\mathrm{OH})(2) \mathrm{D}$, ratio of $1,25(\mathrm{OH})(2) \mathrm{D}$ to $25(\mathrm{OH}) \mathrm{D}$, and prostate cancer aggressiveness. Prostate 79, 1117-1124. doi: 10.1002/pros.23824

Reits, E. A., Hodge, J. W., Herberts, C. A., Groothuis, T. A., Chakraborty, M., Wansley, E. K., et al. (2006). Radiation modulates the peptide repertoire, enhances MHC class I expression, and induces successful antitumor immunotherapy. J. Exp. Med. 203, 1259-1271. doi: 10.1084/jem.20052494

Rodier, F., and Campisi, J. (2011). Four faces of cellular senescence. J. Cell Biol. 192, 547-556. doi: 10.1083/jcb.201009094

Shan, N. L., Wahler, J., Lee, H. J., Bak, M. J., Das Gupta, S., Maehr, H., et al. (2017). Vitamin D compounds inhibit cancer stem-like cells and induce differentiation in triple negative breast cancer. J. Steroid Biochem. Mol. Biol. 173, 122-129. doi: 10.1016/j.jsbmb.2016.12.001

Sharma, K., Goehe, R. W., Di, X., Hicks, M. A. II, Torti, S. V., Torti, F. M., et al. (2014). A novel cytostatic form of autophagy in sensitization of non-small cell lung cancer cells to radiation by vitamin D and the vitamin D analog, EB 1089. Autophagy 10, 2346-2361. doi: 10.4161/15548627.2014.993283

Sherman, M. H., Yu, R. T., Engle, D. D., Ding, N., Atkins, A. R., Tiriac, H., et al. (2014). Vitamin D receptor-mediated stromal reprogramming suppresses pancreatitis and enhances pancreatic cancer therapy. Cell 159, 80-93. doi: 10.1016/j.cell.2014.08.007

Short, S., Fielder, E., Miwa, S., and von Zglinicki, T. (2019). Senolytics and senostatics as adjuvant tumor therapy. Ebiomedicine 41, 683-692. doi: 10.1016/ j.ebiom.2019.01.056 
Simboli-Campbell, M., Narvaez, C. J., van Weelden, K., Tenniswood, M., and Welsh, J. (1997). Comparative effects of 1,25(OH)2D3 and EB1089 on cell cycle kinetics and apoptosis in MCF-7 breast cancer cells. Breast Cancer Res. Treatm. 42, 31-41. doi: 10.1023/a:1005772432465

So, J. Y., and Suh, N. (2015). Targeting cancer stem cells in solid tumors by vitamin D. J. Steroid Biochem. Mol. Biol. 148, 79-85.

Song, M., Nishihara, R., Wang, M., Chan, A. T., Qian, Z. R., Inamura, K., et al. (2016). Plasma 25-hydroxyvitamin D and colorectal cancer risk according to tumor immunity status. Gut 65, 296-304.

Stone, H. B., Peters, L. J., and Milas, L. (1979). Effect of host immune capability on radiocurability and subsequent transplantability of a murine fibrosarcoma. J. Natl. Cancer Inst. 63, 1229-1235.

Sundaram, S., and Gewirtz, D. A. (1999). The vitamin D-3 analog EB 1089 enhances the response of human breast tumor cells to radiation. Radiat. Res. 152, 479-486.

Tauriello, D. V. F., Palomo-Ponce, S., Stork, D., Berenguer-Llergo, A., BadiaRamentol, J., Iglesias, M., et al. (2018). TGF beta drives immune evasion in genetically reconstituted colon cancer metastasis. Nature 554, 538-543.

Tsai, C.-S., Chen, F.-H., Wang, C.-C., Huang, H.-L., Jung, S.-M., Wu, C.-J., et al. (2007). Macrophages from irradiated tumors express higher levels of iNOS, Arginase-I and COX-2, and promote tumor growth. Int. J. Radiat. Oncol. Biol. Phys. 68, 499-507.

Tse, A. K.-W., Zhu, G.-Y., Wan, C.-K., Shen, X.-L., Yu, Z.-L., and Fong, W.-F. (2010). 1 alpha,25-Dihydroxyvitamin D-3 inhibits transcriptional potential of nuclear factor kappa B in breast cancer cells. Mol. Immunol. 47, 1728-1738.

Urashima, M., Ohdaira, H., Akutsu, T., Okada, S., Yoshida, M., Kitajima, M., et al. (2019). Effect of Vitamin D supplementation on relapse-free survival among patients with digestive tract cancers the AMATERASU randomized clinical trial. JAMA J. Am. Med. Assoc. 321, 1361-1369.

Vanpouille-Box, C., Alard, A., Aryankalayil, M. J., Sarfraz, Y., Diamond, J. M., Schneider, R. J., et al. (2017). DNA exonuclease Trex1 regulates radiotherapyinduced tumor immunogenicity. Nat. Commun. 8:15618.

Vanpouille-Box, C., Diamond, J. M., Pilones, K. A., Zavadil, J., Babb, J. S., Formenti, S. C., et al. (2015). TGF beta is a master regulator of radiation therapy-induced antitumor immunity. Cancer Res. 75, 2232-2242.

Vatner, R. E., and Formenti, S. C. (2015). Myeloid-derived cells in tumors: effects of radiation. Semin. Radiat. Oncol. 25, 18-27.

Wei, R., and Christakos, S. (2015). Mechanisms underlying the regulation of innate and adaptive immunity by Vitamin D. Nutrients 7, 8251-8260.

Wesselink, E., Bours, M. J. L., de Wilt, J. H. W., Aquarius, M., Breukink, S. O., Hansson, B., et al. (2020). Chemotherapy and vitamin D supplement use are determinants of serum 25-hydroxyvitamin D levels during the first six months after colorectal cancer diagnosis. J. Steroid Biochem. Mol. Biol. 199:105577.

Whiteside, T. L., Demaria, S., Rodriguez-Ruiz, M. E., Zarour, H. M., and Melero, I. (2016). Emerging opportunities and challenges in cancer immunotherapy. Clin. Cancer Res. 22, 1845-1855.

Wilson, E. N., Bristol, M. L., Di, X., Maltese, W. A., Koterba, K., Beckman, M. J., et al. (2011). A switch between cytoprotective and cytotoxic autophagy in the radiosensitization of breast tumor cells by chloroquine and vitamin D. Horm. Cancer 2, 272-285.

Wu, W. S., Heinrichs, S., Xu, D., Garrison, S. P., Zambetti, G. P., Adams, J. M., et al. (2005). Slug antagonizes p53-mediated apoptosis of hematopoietic progenitors by repressing puma. Cell 123, 641-653.
Wu, X., Hu, W., Lu, L., Zhao, Y., Zhou, Y., Xiao, Z., et al. (2019). Repurposing vitamin $\mathrm{D}$ for treatment of human malignancies via targeting tumor microenvironment. Acta Pharm. Sin. B 9, 203-219.

Xu, Y., Fang, F., St. Clair, D. K., Josson, S., Sompol, P., Spasojevic, I., et al. (2007). Suppression of RelB-mediated manganese superoxide dismutase expression reveals a primary mechanism for radiosensitization effect of 1 alpha,25dihydroxyvitamin D-3 in prostate cancer cells. Mol. Cancer Ther. 6, 2048-2056.

Yang, J., Yan, J., and Liu, B. (2018). Targeting veGF/veGFR to modulate antitumor immunity. Front. Immunol. 9:978. doi: 10.3389/fimmu.2018.00978

Yao, S., Kwan, M. L., Ergas, I. J., Roh, J. M., Cheng, T.-Y. D., Hong, C.-C., et al. (2017). Association of serum level of Vitamin D at diagnosis with breast cancer survival a case-cohort analysis in the pathways study. JAMA Oncol. 3, 351-357.

Ylikomi, T., Laaksi, I., Lou, Y. R., Martikainen, P., Miettinen, S., Pennanen, P., et al. (2002). Antiproliferative action of vitamin D. Vitam. Horm. 64, 357-406.

Yonaga, H., Okada, S., Akutsu, T., Ohdaira, H., Suzuki, Y., and Urashima, M. (2019). Effect modification of Vitamin D supplementation by histopathological characteristics on survival of patients with digestive tract cancer: post hoc analysis of the AMATERASU randomized clinical trial. Nutrients 11:2547.

Yu, X., Liu, Y., Yin, L., Peng, Y., Peng, Y., Gao, Y., et al. (2018). Radiation-promoted CDC6 protein stability contributes to radioresistance by regulating senescence and epithelial to mesenchymal transition. Oncogene 38, 549-563.

Yuan, C., Sato, K., Hollis, B. W., Zhang, S., Niedzwiecki, D., Ou, F.-S., et al. (2019). Plasma 25-Hydroxyvitamin D Levels and survival in patients with advanced or metastatic colorectal cancer: findings from CALGB/SWOG 80405 (Alliance). Clin. Cancer Res. 25, 7497-7505.

Zhang, P., Wei, Y., Wang, L., Debeb, B. G., Yuan, Y., Zhang, J., et al. (2014). ATM-mediated stabilization of ZEB1 promotes DNA damage response and radioresistance through $\mathrm{CH}$ K1. Nat. Cell Biol. 16, 864-875.

Zheng, W., Duan, B., Zhang, Q., Ouyang, L., Peng, W., Qian, F., et al. (2018). Vitamin D-induced vitamin D receptor expression induces tamoxifen sensitivity in MCF-7 stem cells via suppression of Wnt/beta-catenin signaling. Biosci. Rep. 38:BSR20180595.

Zheng, W., Skowron, K. B., Namm, J. P., Burnette, B., Fernandez, C., Arina, A., et al. (2016). Combination of radiotherapy and vaccination overcomes checkpoint blockade resistance. Oncotarget 7, 43039-43051.

Zheng, Y., Trivedi, T., Lin, R. C. Y., Fong-Yee, C., Nolte, R., Manibo, J., et al. (2017). Loss of the vitamin $\mathrm{D}$ receptor in human breast and prostate cancers strongly induces cell apoptosis through downregulation of Wnt/beta-catenin signaling. Bone Res. 5:17023.

Zhou, Q., Qin, S., Zhang, J., Zhon, L., Pen, Z., and Xing, T. (2017). 1,25(OH)(2)D3 induces regulatory $\mathrm{T}$ cell differentiation by influencing the VDR/PLC-gamma 1/TGF-beta 1/pathway. Mol. Immunol. 91, 156-164.

Conflict of Interest: The authors declare that the research was conducted in the absence of any commercial or financial relationships that could be construed as a potential conflict of interest.

Copyright (c) $2021 \mathrm{Yu}$, Liu, Zhang, Wang and Cheng. This is an open-access article distributed under the terms of the Creative Commons Attribution License (CC BY). The use, distribution or reproduction in other forums is permitted, provided the original author(s) and the copyright owner(s) are credited and that the original publication in this journal is cited, in accordance with accepted academic practice. No use, distribution or reproduction is permitted which does not comply with these terms. 